\title{
Bone Mineral Density in Relation to Polymorphism at the Vitamin D Receptor Gene Locus
}

Frank G. Hustmyer, Munro Peacock, Siu Hui, C. Conrad Johnston, and Joe Christian*

Departments of Medicine and *Medical \& Molecular Genetics, Indiana University School of Medicine, Indianapolis, Indiana 46202

\begin{abstract}
Polymorphism at the vitamin D receptor gene was examined in relation to bone mineral density (BMD) at spine, femur, and forearm in 86 monozygotic (MZ) and 39 dizygotic (DZ) adult female twins. All were white, 63 pairs (44 MZ, $19 \mathrm{DZ}$ ) were premenopausal, and 43 pairs (31 MZ, $12 \mathrm{DZ}$ ) were discordant for age at menopause or use of estrogen.

Each individual of the $\mathrm{DZ}$ pairs and one individual of MZ pairs was genotyped for ApaI, BsmI, and TaqI polymorphism at the vitamin D receptor gene locus using Southern hybridization.

Intraclass correlations for $\mathrm{BMD}$ in $\mathrm{MZ}$ and $\mathrm{DZ}$ twin pairs indicated that heritability accounted for over $70 \%$ of BMD. There was no relationship between genotype for any of the three polymorphisms and BMD at any skeletal site in the twin population, considered either as a total population, both with and without twins discordant for age at menopause or use of estrogen, or as a premenopausal population. In $\mathrm{DZ}$ twin pairs discordant for alleles for the three polymorphisms, no allele was associated with higher or lower BMD.

It is concluded that in this population of healthy adult females there was no relationship between these polymorphisms at the vitamin D receptor gene locus and BMD. (J. Clin. Invest. 1994. 94:2130-2134.) Key words: twins • heritability • osteoporosis • age-related bone loss • fractures

\section{Introduction}

Density of bone is strongly inherited. From studies of monozygotic (MZ) ${ }^{1}$ and dizygotic (DZ) twins, inheritance is estimated to account for between $60 \%$ and $80 \%$ of the bone mineral density (BMD) in both men (1) and women (2, 3). BMD is a major determinant of bone strength (4-6). Within the normal range of $\mathrm{BMD}$, a decrease of one standard deviation approximately doubles the risk of fracture $(7-10)$, indicating that the
\end{abstract}

Address correspondence to Munro Peacock, M.D., University Hospital, 5595, 550 N. University Blvd., Indianapolis, IN 46202-5250. 1994.

Received for publication 4 April 1994 and in revised form 14 June

1. Abbreviations used in this paper: $\mathrm{BMD}$, bone mineral density; $\mathrm{DZ}$, dizygotic; MZ, monozygotic; VDR, vitamin D receptor.

J. Clin. Invest.

(c) The American Society for Clinical Investigation, Inc.

$0021-9738 / 94 / 11 / 2130 / 05 \$ 2.00$

Volume 94, November 1994, 2130-2134 risk of developing age-related osteoporotic fractures is, in part, heritable.

Identification of genetic markers that relate to inheritance of BMD in the normal population is of central importance for both identifying subjects at risk of age-related osteoporosis and understanding the mechanisms involved in the heritability of BMD. In a study involving both healthy women and $\mathrm{MZ}$ and DZ adult twins from Australia, Morrison et al. (11) have shown a strong relationship between polymorphism at the vitamin D receptor (VDR) gene and BMD at the spine. A similar but weaker relationship was present at the hip. These investigators reported that, in their twin population, homozygotes for the VDR gene alleles defined by the restriction endonuclease BsmI differed in spinal BMD by over one standard deviation of the normal population. Such a difference suggests that the genetic variation in BMD of the normal population is largely accounted for by polymorphism at the VDR gene locus. Furthermore, in their healthy pre- and postmenopausal women, the difference in BMD between the two groups homozygous for the VDR gene alleles resulted in a 10-yr difference in spine density and an 8-yr difference in hip density.

In addition to BsmI (12), restriction fragment length polymorphisms at the VDR gene have been described with the endonucleases ApaI (13), EcoRV (12), and TaqI (14). In this study, we have examined the relationship between the genotypes defined by polymorphisms for ApaI, BsmI, and TaqI at the VDR gene, and BMD at the lumbar spine, upper femur, and forearm in a population of healthy adult female MZ and DZ twins of Caucasian origin.

\section{Methods}

Patients. 86 monozygotic and 39 dizygotic pairs of adult female twins were recruited from the Indiana University Twin Panel. The twins were healthy and had no known disease of bone. Height, weight, age, menopausal age, and use of estrogen preparations were recorded, blood was drawn, and BMD measured. The protocol was approved by the Institutional Review Board of Indiana University, Purdue University at Indianapolis.

Bone mineral density. BMD at the lumbar spine (L2-L4), and upper femur (neck, Ward's triangle, greater trochanter), was measured by dual photon absorptiometry, and at proximal and distal sites of the forearm by single photon absorptiometry (Lunar Corp., Madison, WI).

Genotyping. DNA was extracted from blood and $10 \mu \mathrm{g}$ DNA digested for $3 \mathrm{~h}$ in a volume of $200 \mu \mathrm{l}$ with $80 \mathrm{U}$ of the restriction endonucleases, ApaI, TaqI (Boehringer Mannheim Corp., Indianapolis, IN), or BsmI (New England Biolabs Inc., Beverly MA) at temperatures recommended by the manufacturers. DNA was extracted by ethanol precipitation; fractionated using $0.8 \%$ agarose gel electrophoresis, and transferred to nitrocellulose filters (Schleicher \& Schuell, Inc., Keene, $\mathrm{NH}$ ). Filter membranes were prehybridized; the filters were then hybridized with the ${ }^{32} \mathrm{P}$-labeled probe for $18 \mathrm{~h}$ at $42^{\circ} \mathrm{C}$, washed, and autoradio- 
Table I. Mean (SD) Height, Weight, and Age of the Total Twin Population (Total), in the Subpopulation after Removal of Twin Pairs Discordant for Estrogen or Age at Menopause (Total [Menopause/Estrogen]), and the Subpopulation of Premenopausal Twin Pairs (Premenopausal)

\begin{tabular}{ccccccccc}
\hline & \multicolumn{2}{c}{ Total } & & \multicolumn{2}{c}{ Total (Menop/Estr) } & & \multicolumn{2}{c}{ Premenopausal } \\
\cline { 2 - 3 } \cline { 8 - 9 } & $\mathrm{MZ}$ & $\mathrm{DZ}$ & & $\mathrm{MZ}$ & $\mathrm{DZ}$ & & $\mathrm{MZ}$ & $\mathrm{DZ}$ \\
\hline$n$ (pairs) & 86 & 39 & & 55 & 27 & & 44 & 19 \\
Height & 162.9 & 164.1 & & 162.8 & 165.1 & & 163.2 & 166.0 \\
$(\mathrm{~cm})$ & $(6.1)$ & $(6.2)$ & & $(6.3)$ & $(6.3)$ & & $(5.8)$ & $(6.8)$ \\
Weight & 64.0 & $70.4 *$ & & 63.1 & $71.4 *$ & & 61.9 & $74.2 *$ \\
$(\mathrm{~kg})$ & $(10.5)$ & $(16.2)$ & & $(11.8)$ & $(17.5)$ & & $(11.1)$ & $(19.7)$ \\
Age & 43.9 & 43.0 & & 40.0 & 40.8 & & 35.4 & 35.0 \\
$(\mathrm{yr})$ & $(11.8)$ & $(11.7)$ & & $(11.6)$ & $(11.5)$ & & $(6.3)$ & $(4.1)$ \\
& & & & & & & & \\
\hline
\end{tabular}

Significance between $\mathrm{MZ}$ and $\mathrm{DZ}$ twins, ${ }^{*} P<0.05$.

graphed for $24 \mathrm{~h}$. The probe, hVDR-ORF, is a $1.4 \mathrm{~kb}$ cDNA encoding the full length human VDR. It was isolated from HL-60 human promyelocytic leukemia cell line by reverse transcription-PCR technique and cloned as an EcoRI fragment into pBluescript $\mathrm{KS}+$ (Stratagene, La Jolla, CA) (15). The VDR-ORF cDNA was radiolabeled with $\left[\alpha^{32} \mathrm{P}\right] \mathrm{dCTP}(3,000 \mathrm{Ci} / \mathrm{mmol}, 10 \mathrm{mCi} / \mathrm{ml}$, Amersham Corp., Arlington Heights, IL) using the oligolabeling method (Pharmacia Fine Chemicals, Piscataway, NJ). The alleles were named as previously described (14).

Analysis and Statistics. To examine whether discordance for age at menopause, use of estrogen, or postmenopausal status influenced the relationship between polymorphisms at the VDR gene and BMD, the twin population was analyzed as three separate groups. First, they were analyzed as a total population (total) irrespective of history of estrogen use and age at menopause. Second, they were analyzed as a subgroup with all twin pairs discordant for age at menopause (difference between pairs of $2 \mathrm{yr}$ and more at age of menopause, if they were within $5 \mathrm{yr}$ from menopause at the time of the BMD measurement), or use of estrogen removed from the total population (total - menopause:estrogen). Third, all premenopausal twin pairs were analyzed as a separate subgroup (premenopausal).

The degree of relationship in the $\mathrm{MZ}$ and $\mathrm{DZ}$ twin pairs was estimated by intraclass correlations, $\mathrm{rMZ}$, and $\mathrm{rDZ}$, respectively, where $\mathrm{rMZ}=(\mathrm{aMZ}-\mathrm{wMZ}) /(\mathrm{aMZ}+\mathrm{wMZ})$, and $\mathrm{aMZ}$ is among pair mean squares and wMZ is within pair mean squares (16). rDZ is similarly calculated. Heritability $\left(\mathrm{H}^{2}\right)$ was estimated as 2 (rMZ - rDZ) (17). The rDZ for twins discordant and concordant for genotype for the three polymorphisms was also calculated.

Differences in BMD among the three genotypes for the three polymorphisms were tested using ANOVA. Differences in BMD among genotypes adjusting for age, height, and weight were tested using analysis of covariance. The direction of the differences in BMD between DZ twins discordant for genotype for the three polymorphisms was assessed using paired $t$ tests. $t$ tests were used to assess differences in mean age, height, and weight between $\mathrm{MZ}$ and $\mathrm{DZ}$ twins. The expected frequency of discordant and concordant DZ twins for genotype for the three polymorphisms was determined using the ITO method as described by Li (18).

\section{Results}

There were $44 \mathrm{MZ}$ and $19 \mathrm{DZ}$ premenopausal twin pairs, and $31 \mathrm{MZ}$ and $12 \mathrm{DZ}$ postmenopausal pairs were using estrogen or were discordant for age of menopause (Table I). There were no significant differences in the mean age between all $\mathrm{MZ}$ and $\mathrm{DZ}$ twin pairs (total), with the twin pairs discordant for age at
Table II. Intraclass Correlations (rMZ, rDZ) and Heritability for $B M D\left(\mathrm{~g} / \mathrm{cm}^{2}\right)$, at Spine, Femur, and Forearm, $\mathrm{g} / \mathrm{cm}^{2}$ in the Total Twin Population (Total), in the Subpopulation after Removal of Twin Pairs Discordant for Age at Menopause and Use of Estrogen (Total [Menopause/Estrogen]), and in the Subpopulation of Premenopausal Twin Pairs (Premenopausal)

\begin{tabular}{|c|c|c|c|c|c|c|}
\hline & \multirow{2}{*}{$\frac{\text { Spine }}{\text { L2-4 }}$} & \multicolumn{3}{|c|}{ Upper femur } & \multicolumn{2}{|c|}{ Forearm } \\
\hline & & Neck & Ward & Troc & Distal & Proximal \\
\hline \multicolumn{7}{|l|}{ Total } \\
\hline $\mathrm{rMZ}$ & 0.85 & 0.77 & 0.80 & 0.77 & 0.80 & 0.84 \\
\hline rDZ & 0.41 & 0.43 & 0.38 & 0.26 & 0.43 & 0.64 \\
\hline $\mathbf{H}^{2}$ & 0.88 & 0.68 & 0.84 & 1.02 & 0.74 & 0.40 \\
\hline \multicolumn{7}{|c|}{ Total (Menop/Estr) } \\
\hline rMZ & 0.92 & 0.81 & 0.86 & 0.84 & 0.84 & 0.77 \\
\hline $\mathrm{rDZ}$ & 0.13 & 0.36 & 0.32 & 0.23 & 0.45 & 0.60 \\
\hline $\mathrm{H}^{2}$ & 1.58 & 0.90 & 1.08 & 1.22 & 0.75 & 0.34 \\
\hline \multicolumn{7}{|c|}{ Premenopausal } \\
\hline $\mathrm{rMZ}$ & 0.89 & 0.73 & 0.78 & 0.78 & 0.82 & 0.71 \\
\hline $\mathrm{rDZ}$ & 0.38 & 0.28 & 0.17 & 0.24 & 0.41 & 0.45 \\
\hline $\mathrm{H}^{2}$ & 1.02 & 0.90 & 1.22 & 1.08 & 0.82 & 0.52 \\
\hline
\end{tabular}

$\mathrm{H}^{2}=2(\mathrm{rMZ}-\mathrm{rDZ})$

menopause or use of estrogen removed (total minus [menopause/estrogen]), or as premenopausal twin pairs (premenopausal). The DZ twins, however, were taller and significantly heavier $(P<.05)$ than MZ twins in each of the three population groups examined.

Intraclass correlations for BMD at spine, upper femur, and distal site of the forearm in $\mathrm{MZ}$ twins were about twice that of the corresponding $\mathrm{DZ}$ twins, indicating that heritability $\left(\mathrm{H}^{2}\right)$ accounted for over $70 \%$ of BMD at these sites (Table II). At the proximal site of the forearm, heritability accounted for only $\sim 40 \%$ of the BMD. In the subpopulation that did not contain pairs of twins discordant for age at menopause or use of estrogen, and in the subpopulation of premenopausal twins, the rMZ was, in general, more than twice the corresponding rDZ.

The genotype and allele frequencies for ApaI, BsmI, and TaqI were similar in $\mathrm{MZ}$ and DZ pairs (Table III). The genotypes were in Hardy-Weinberg equilibrium and the numbers of concordant and discordant $\mathrm{DZ}$ twins were not significantly different from that expected (18). In 39 pairs of $\mathrm{DZ}$ twins, 17 were discordant for ApaI, 14 for BsmI, and 15 for TaqI. In 12 pairs, there was discordance for all three polymorphisms; two pairs were discordant for BsmI and TaqI but not for ApaI; one pair was discordant for TaqI only; and five pairs were discordant for ApaI only. BsmI, TaqI, and ApaI polymorphisms were related very closely, with $98 \%$ of subjects concordant for genotype for BsmI and TaqI, and $79 \%$ for BsmI and ApaI.

BMD at spine, femur, and forearm of all subjects in the $\mathrm{MZ}$ and $\mathrm{DZ}$ twin populations combined, in relation to the genotypes for each of the three polymorphisms, is shown in Table IV and Fig. 1. There was no significant difference in BMD at any of the skeletal sites between the three genotypes for any of the three polymorphisms. Correcting BMD for the effect of height, weight, and age did not alter these relationships between genotype and BMD, and all remained nonsignificant. The statistical power of this study, based on the results reported by Morrison et al. (11), to detect a relationship between spinal BMD and BsmI genotype, ranged from over $99 \%$ in our total twin popula- 
Table III. Genotype and Allele Frequencies for ApaI, BsmI, and TaqI Polymorphisms in the Twin Population

\begin{tabular}{|c|c|c|c|c|c|c|c|c|c|}
\hline & \multicolumn{9}{|c|}{ Genotype frequencies $\%(1=\mathrm{AA}, 2=\mathrm{Aa}, 3=\mathrm{aa}$, etc. $)$} \\
\hline & \multicolumn{3}{|c|}{ MZ twins } & \multicolumn{3}{|c|}{ DZ twins } & \multicolumn{3}{|c|}{ All twins } \\
\hline & Apa & Bsm & Taq & Apa & Bsm & Taq & Apa & Bsm & Taq \\
\hline 1 & 26 & 14 & 14 & 32 & 17 & 15 & 28 & 15 & 14 \\
\hline 2 & 50 & 48 & 47 & 42 & 55 & 53 & 47 & 50 & 49 \\
\hline 3 & 24 & 38 & 39 & 26 & 28 & 32 & 25 & 35 & 37 \\
\hline \multirow[t]{3}{*}{ Total $n$} & 164 & 170 & 172 & 78 & 78 & 78 & 242 & 248 & 250 \\
\hline & & & \multicolumn{7}{|c|}{ Allele frequencies $\%$} \\
\hline & & & \multicolumn{2}{|c|}{ MZ twins } & \multicolumn{3}{|c|}{ DZ twins } & \multicolumn{2}{|c|}{ All twins } \\
\hline \multicolumn{3}{|l|}{ A } & \multicolumn{2}{|r|}{50} & \multicolumn{3}{|c|}{53} & \multicolumn{2}{|r|}{51} \\
\hline \multicolumn{3}{|l|}{$\mathbf{a}$} & \multicolumn{2}{|r|}{50} & \multicolumn{3}{|c|}{47} & \multicolumn{2}{|r|}{49} \\
\hline \multicolumn{3}{|c|}{ Total chromosomes } & \multicolumn{2}{|r|}{328} & \multicolumn{3}{|c|}{156} & \multicolumn{2}{|c|}{484} \\
\hline \multicolumn{3}{|l|}{ B } & \multicolumn{2}{|r|}{38} & \multicolumn{3}{|c|}{44} & \multicolumn{2}{|r|}{40} \\
\hline \multicolumn{3}{|l|}{ b } & \multicolumn{2}{|r|}{62} & \multicolumn{3}{|c|}{56} & \multicolumn{2}{|r|}{60} \\
\hline \multicolumn{3}{|c|}{ Total chromosomes } & \multicolumn{2}{|r|}{340} & \multicolumn{3}{|c|}{156} & \multicolumn{2}{|c|}{496} \\
\hline \multicolumn{3}{|l|}{$\mathrm{T}$} & \multicolumn{2}{|r|}{37} & & 42 & & & 39 \\
\hline $\mathbf{t}$ & & & & 63 & & 58 & & & 61 \\
\hline Total ch & mosc & & & 344 & & 156 & & & 500 \\
\hline
\end{tabular}

tion to over $92 \%$ in our smallest subgroup, the premenopausal twin population (Table V).

The relationships between genotype and spinal BMD for the three polymorphisms in the $\mathrm{DZ}$ twins that were discordant for the alleles are shown in Fig. 2. In no instance was there a significant relationship between spinal BMD and genotype, and the direction of the differences in BMD between twin pairs was random in relation to genotype. The statistical power of this study to detect an effect of genotype on the direction of difference in spinal BMD between DZ twins discordant for BsmI genotype as reported by Morrison et al. (11) ranged from over $99 \%$ in our total discordant $\mathrm{DZ}$ twin pairs to $78 \%$ in the five pairs of premenopausal discordant DZ twins (Table VI). Moreover, our results ( 7 of 13$)$ differed significantly $(P=0.0056$, Fisher's exact test) from those of Morrison et al. (21 of 22) in the proportion of pairs with spinal BMD in the direction predicted by genotype. Restricting the analysis to the nine pairs concordant for estrogen and menopause the proportion of correctly predicted pairs (four of nine) remained significantly different from that of Morrison et al. $(P=0.0038)$.

Similar results were found for the three sites in the upper femur and the two sites in the forearm. In one pair of discordant $\mathrm{DZ}$ twins, the difference in BMD at the spine was almost $50 \%$ and was considered to be an outlier. Analysis of the data without this pair also showed no relationship between BMD and genotype. Furthermore, the intraclass correlations for BMD at all sites were not significantly different between DZ twins concordant and discordant for genotype for the three polymorphisms, and were significantly lower than the corresponding rMZ values.

\section{Discussion}

In our study, BMD and, to a lesser extent, height were highly heritable, with the corresponding $\mathrm{rMZ}$ and $\mathrm{rDZ}$ values similar to those previously published $(2,3)$. However, there was no association between BMD at spine, femur, or forearm and the three polymorphisms at the VDR gene defined by the restriction endonuclease BsmI, or ApaI and TaqI. No particular genotype explained the differences in bone density between the discordant DZ twin pairs. Moreover, the intraclass correlations for BMD in DZ twins concordant and discordant for genotype were similar and always less than those for $\mathrm{MZ}$ twins.

These results are in marked contrast to the findings of Morrison et al. (11), who found that the presence of allele " $b$ ", was associated with greater bone density. In their twin study the effect of allele $b$ accounted for most of BMD that is derived from inheritance, and, in DZ twins concordant for genotype, the intraclass correlation coefficients were similar to those of the $\mathrm{MZ}$ twins, who have $100 \%$ of genes in common. For example, Morrison et al. (11) showed that, in individuals with genotype $\mathrm{bb}$, the mean spinal BMD of their total twin population was $1.25 \mathrm{~g} / \mathrm{cm}^{2}, 0.16 \mathrm{~g} / \mathrm{cm}^{2}$ higher than genotype $\mathrm{BB}$, whereas in our individuals with bb genotype, the mean spinal BMD was $1.12 \mathrm{~g} / \mathrm{cm}^{2}, 0.04 \mathrm{~g} / \mathrm{cm}^{2}$ lower than our BB group. Although our BB group was somewhat smaller $(n=37)$ than theirs ( $n=53)$, our bb group was larger $(n=85)$ than theirs $(n=68)$, and therefore, the differences between the two studies cannot be due to sample size. Moreover, correcting for age, weight, or height as covariants did not alter the significance of any results; nor is it likely to be due to lack of power. In our total twin population, we had between 99 and $92 \%$ power, and in our DZ twin discordant for genotype, we had between 99 and $78 \%$ power, depending on the subgroups examined, to detect the effect-sizes reported in the Australian study.

The frequencies of genotypes and alleles in our twin population were very similar to those we have previously reported for the general white population in Indiana from which our twins are largely drawn (14). A frequency of $22 \%$ for the BB genotype reported by Morrison et al. (11) in their twins was higher than the $16 \%$ they found in the general population and higher than the $15 \%$ we found in our twin population. Also, a frequency of $28 \%$ for the bb genotype in the Australian twins is less than the $36 \%$ frequency in the Australian population and the $34 \%$ of our twin population. These differences in genotype frequency may represent differences in genetic background of the twin populations of Indiana and Australia, because, as we have shown, there are racial differences in the BsmI allele frequency (14). However, both populations are of north European ancestry, and racial differences are unlikely to be responsible. Another difference between the two studies is that in the Australian data there is an anomaly in the number of $\mathrm{DZ}$ twins discordant for genotype. There were seven discordant twin pairs $(B B, b b)$, whereas, only 1.7 is expected based upon their reported gene frequencies $\left(\mathrm{x}_{1}^{2}=16.4, P<0.001\right)(18)$.

Polymorphism was established by Southern hybridization in our study, using a 1.4-kb cDNA probe encoding the fulllength VDR (15), whereas in the Australian study polymorphism was established by PCR of the DNA in the region from exon 7 to the $3^{\prime}$ untranslated region, based on studies using a 2.1-kb cDNA probe (19). To exclude any difference in genotype classification due to the probes, we have checked, in a blinded study, 36 of our samples (12 of each genotype) with our $1.4-\mathrm{kb}$ probe ( -70 to $1305 \mathrm{nt}$ ) (15) and a $2.0-\mathrm{kb}$ probe ( +5 to $2005 \mathrm{nt}$ ) (20) a method very similar to that used by Morrison et al. (12), using Southern hybridization. As expected, both probes gave exactly the same classification of genotypes. The similarity of the results obtained with BsmI, TaqI, and ApaI indicates that misclassification of cases due to incomplete 
Table IV. Bone Mineral Density, $\mathrm{g} / \mathrm{cm}^{2}$, at the Spine, Femur, and Forearm in Relation to Genotype Defined by ApaI, BsmI, and TaqI in the Total Twin Population (Total), Subpopulation after Removal of Twins Discordant for Age at Menopause or Estrogen Use (Total [Menopause/Estrogen]), and in the Subpopulation of Premenopausal Twins (Premenopausal)

\begin{tabular}{|c|c|c|c|c|c|c|c|c|c|c|c|c|c|c|c|}
\hline \multirow{2}{*}{\multicolumn{3}{|c|}{$\frac{\text { Spine }}{\text { L2-4 }}$}} & \multicolumn{7}{|c|}{ Upper femur } & \multicolumn{6}{|c|}{ Forearm } \\
\hline & & & & Neck & & Wa & & $\operatorname{Tr}$ & & & Distal & & & Proximal & \\
\hline$n$ & mean & SD & $n$ & mean & SD & mean & SD & mean & SD & $n$ & mean & SD & $n$ & mean & SD \\
\hline
\end{tabular}

Total $(n=250)$

\begin{tabular}{|c|c|c|c|c|c|c|c|c|c|c|c|c|c|c|c|c|}
\hline $\mathrm{AA}$ & 67 & 1.15 & .15 & 66 & .84 & .13 & .70 & .15 & .69 & .11 & 62 & .37 & .07 & 62 & .65 & .08 \\
\hline $\mathrm{Aa}$ & 112 & 1.17 & .14 & 108 & .88 & .12 & .74 & .13 & .71 & .10 & 110 & .38 & .06 & 112 & .67 & .06 \\
\hline aa & 59 & 1.10 & .16 & 59 & .85 & .13 & .72 & .16 & .70 & .13 & 59 & .39 & .06 & 59 & .68 & .08 \\
\hline BB & 37 & 1.16 & .17 & 37 & .85 & .13 & .72 & .14 & .70 & .12 & 35 & .37 & .07 & 35 & .66 & .09 \\
\hline $\mathrm{Bb}$ & 122 & 1.16 & .14 & 117 & .88 & .13 & .74 & .14 & .70 & .10 & 121 & .38 & .06 & 123 & .67 & .06 \\
\hline bb & 85 & 1.12 & .16 & 85 & .85 & .13 & .72 & .15 & .71 & .12 & 81 & .38 & .06 & 81 & .67 & .07 \\
\hline TT & 36 & 1.15 & .16 & 36 & .85 & .13 & .72 & .14 & .69 & .12 & 34 & .37 & .07 & 34 & .66 & .09 \\
\hline $\mathrm{Tt}$ & 118 & 1.17 & .14 & 113 & .87 & .13 & .74 & .15 & .70 & .10 & 117 & .38 & .06 & 119 & .67 & .06 \\
\hline $\mathrm{tt}$ & 92 & 1.12 & .15 & 92 & .86 & .12 & .72 & .15 & .71 & .12 & 88 & .38 & .06 & 88 & .67 & .07 \\
\hline
\end{tabular}

Total (menopause/estrogen)

\begin{tabular}{|c|c|c|c|c|c|c|c|c|c|c|c|c|c|c|c|c|}
\hline AA & 43 & 1.15 & .15 & 43 & .85 & .13 & .71 & .14 & .69 & .10 & 38 & .37 & .06 & 38 & .67 & .07 \\
\hline $\mathrm{Aa}$ & 78 & 1.18 & .13 & 74 & .89 & .12 & .76 & .13 & .71 & .10 & 76 & .39 & .06 & 78 & .68 & .06 \\
\hline aa & 35 & 1.10 & .18 & 35 & .85 & .16 & .73 & .19 & .70 & .16 & 36 & .38 & .07 & 36 & .67 & .08 \\
\hline BB & 25 & 1.19 & .15 & 25 & .86 & .13 & .73 & .13 & .69 & .10 & 23 & .37 & .06 & 23 & .69 & .08 \\
\hline $\mathrm{Bb}$ & 82 & 1.17 & .13 & 78 & .89 & .12 & .76 & .14 & .71 & .10 & 81 & .39 & .06 & 83 & .69 & .06 \\
\hline bb & 51 & 1.12 & .18 & 51 & .84 & .14 & .72 & .17 & .70 & .14 & 48 & .37 & .07 & 48 & .65 & .07 \\
\hline TT & 24 & 1.18 & .13 & 24 & .86 & .13 & .73 & .13 & .69 & .10 & 22 & .37 & .06 & 22 & .69 & .08 \\
\hline $\mathbf{T t}$ & 79 & 1.17 & .13 & 75 & .89 & .12 & .76 & .14 & .71 & .10 & 78 & .39 & .06 & 80 & .68 & .06 \\
\hline $\mathbf{t t}$ & 57 & 1.12 & .17 & 57 & .85 & .14 & .72 & .16 & .70 & .13 & 54 & .37 & .06 & 54 & .66 & .07 \\
\hline \multicolumn{17}{|c|}{ Premenopausal $(n=126)$} \\
\hline AA & 31 & 1.19 & .12 & 31 & .88 & .12 & .76 & .12 & .70 & .10 & 29 & .39 & .05 & 29 & .70 & .05 \\
\hline $\mathrm{Aa}$ & 62 & 1.19 & .11 & 58 & .91 & .11 & .78 & .11 & .71 & .09 & 61 & .39 & .06 & 63 & .69 & .05 \\
\hline aa & 25 & 1.16 & .12 & 25 & .90 & .13 & .79 & .16 & .74 & .14 & 26 & .41 & .05 & 26 & .69 & .07 \\
\hline BB & 21 & 1.19 & .12 & 21 & .87 & .13 & .75 & .12 & .69 & .10 & 19 & .39 & .06 & 19 & .71 & .06 \\
\hline $\mathbf{B b}$ & 66 & 1.19 & .11 & 62 & .92 & .10 & .80 & .11 & .72 & .09 & 67 & .40 & .06 & 69 & .70 & .05 \\
\hline bb & 33 & 1.17 & .12 & 33 & .89 & .13 & .77 & .15 & .73 & .13 & 32 & .39 & .05 & 32 & .67 & .06 \\
\hline TT & 21 & 1.19 & .12 & 21 & .87 & .13 & .75 & .12 & .69 & .10 & 19 & .39 & .06 & 19 & .71 & .06 \\
\hline $\mathrm{Tt}$ & 62 & 1.20 & .11 & 58 & .92 & .10 & .80 & .11 & .72 & .09 & 63 & .40 & .06 & 65 & .70 & .05 \\
\hline $\mathrm{tt}$ & 39 & 1.16 & .12 & 39 & .89 & .12 & .77 & .14 & .73 & .12 & 38 & .39 & .06 & 38 & .67 & .06 \\
\hline
\end{tabular}

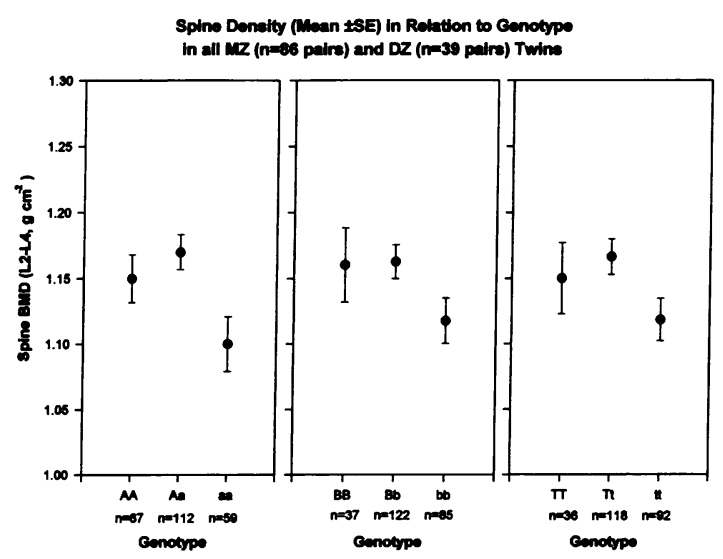

Figure 1. Spinal BMD, (mean \pm SEM) in relation to genotype for ApaI, BsmI, and TaqI in MZ ( $n=87$ pairs) and $\mathrm{DZ} \mathrm{(} n=39$ pairs) adult female twins considered as a total group. digestion with BsmI is not a cause of the differences in our findings from those of Morrison et al (11).

In both studies, BMD was measured by dual-photon absorp-

Table V. Power to Detect a Relationship betweeen Spinal BMD and BsmI Genotype in the Twin Population and Subpopulations Described in Table IV Using Mean Spinal BMD of 1.09, 1.18, and $1.25 \mathrm{~g} / \mathrm{cm}^{2}$ for $\mathrm{BB}, \mathrm{Bb}$, and $\mathrm{bb}$ Genotypes Respectively from Morrison et al. (11) and a Within-group Standard Deviation of $0.17 \mathrm{~g} / \mathrm{cm}^{2}$ from This Study

\begin{tabular}{lrrrr}
\hline & \multicolumn{3}{c}{ Genotype sample size } & \\
\cline { 2 - 4 } & BB & Bb & bb & Power \\
\hline Population & 37 & 122 & 85 & $>99 \%$ \\
Total (menopause/estrogen) & 25 & 82 & 51 & $>97 \%$ \\
Premenopausal & 21 & 66 & 33 & $>92 \%$ \\
& & & & \\
\hline
\end{tabular}

Estimates were based on one-way ANOVA at a 5\% significance level. 
Table VI. Power to Detect an Effect of BsmI Genotype on the Direction of Difference in Spinal BMD between DZ Twins Discordant for Genotype Based on the Report of Morrison et al. (11) that in 21 of 22 Discordant DZ Pairs Higher BMD Was Associated with the $b$ Allele

\begin{tabular}{lcc}
\hline & $\begin{array}{c}\text { Number of discordant } \\
\text { DZ pairs }\end{array}$ & Power \\
\hline Total & 13 & $>99 \%$ \\
Total (menopause/estrogen) & 9 & $>93 \%$ \\
Premenopausal & 5 & $>78 \%$ \\
\hline
\end{tabular}

Estimates were based on one-tailed exact binomial tests at 5\% significance level.

tiometry using Lunar equipment, although in the Australian study DPA and dual $\mathrm{x}$-ray absorptiometry, which measures slightly higher than DPA, measurements were combined. It is usual, however, to measure both twin pairs together, and thus it is unlikely that the higher spinal BMD of subjects with the bb genotype in the Australian study is explained by measurement techniques. The ages of the two study populations were very similar, as were the percentages of twin pairs who were pre- or postmenopausal. In the Australian study, 13 male twin pairs were included, but because there is no sex difference in the frequency of the alleles, this should not account for the differences in the results between the two studies. The Australian study excluded twins who were discordant for estrogen use, who differed by more than two years at age of menopause, and who had degenerative joint disease of the spine (personal communication). Excluding twin pairs who were discordant for age at menopause or use of estrogen, or excluding all postmenopausal twins, had no substantive effect on our results. We did not exclude any twin pairs because of spinal arthritis, but half of our twin pairs were premenopausal and all twins were reportedly healthy.

It is not clear at present why two very similar studies show such marked differences in results. They may arise from differences in subject selection that are not, at present, obvious. On the other hand, it may be that VDR polymorphism is linked to another gene locus that regulates bone density, and that this

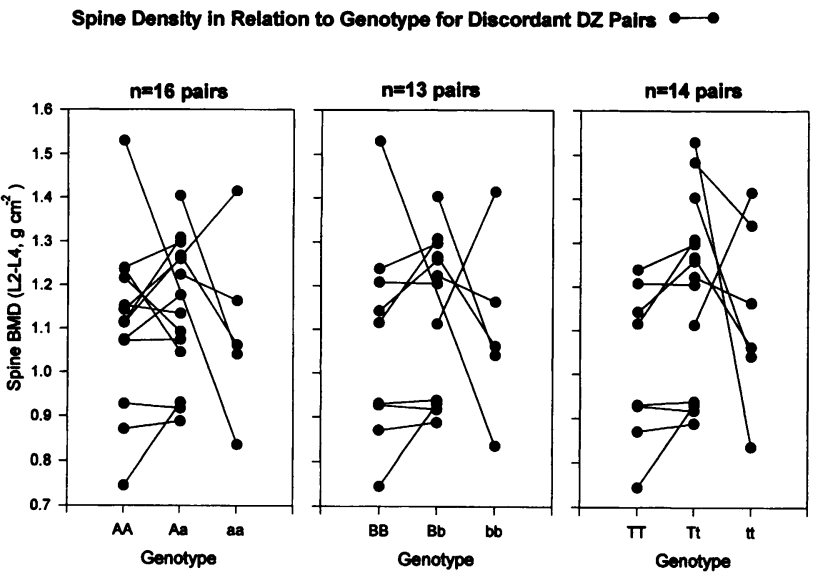

Figure 2. Spinal BMD in relation to genotype for $\mathrm{DZ}$ twin pairs discordant for ApaI, BsmI, and TaqI. linkage may be obscured by environmental factors that are peculiar to certain populations.

\section{Acknowledgments}

We gratefully acknowledge the following for their contributions: advice on population genetics by Michael Conneally, Ph.D.; polymorphism by Jay Tischfield, Ph.D., and Edward Hodes, M.D., Ph.D; provision of the VDR probes by Hector DeLuca, Ph.D., Mark Haussler, Ph.D., and Kerr Whitfield, Ph.D.; data management and analysis by Terri Reister and Chris Schaefer; and typing of the manuscript by Sharon Cromer.

This study was supported by grants PO1 AG05793 and PHS MO1RROO750.

\section{References}

1. Christian, J. C., C. Slemenda, and C. C. Johnston, Jr., 1989. Heritability of bone mass: a longitudinal study in aging male twins. Am. J. Hum. Genet. 44:429433.

2. Slemenda, C. W., J. C. Christian, C. J. Williams, J. A. Norton, and C. C. Johnston, Jr. 1991. Genetic determinants of bone mass in adult women: a reevaluation of the twin model and the potential importance of gene interaction on heritability estimates. J. Bone Miner. Res. 6:561-567.

3. Pocock, N. A., J. A. Eisman, J. L. Hopper, M. G. Yeates, P. N. Sambrook, and S. Ebert. 1987. Genetic determinants of bone mass in adults: a twin study. J. Clin. Invest. 80:706-710.

4. Smith, C. B., and D. A. Smith. 1976. Relations between age, mineral density and mechanical properties of human femoral compacta. Acta Orthop. Scand. 47:496-502.

5. Dalen, N., L-G. Hellstrom, and B. Jacobson. 1976. Bone mineral content and mechanical strength of the femoral neck. Acta Orthop. Scand. 47:503-508.

6. Hansson, T., B. Roos, and A. Nachemson. 1980. The bone mineral content and ultimate compressive strength of lumbar vertebrae. Spine. 5:46-55.

7. Hui, S. L., C. W. Slemenda, and C. C. Johnston, Jr. 1989. Baseline measurement of bone mass predicts fracture in white women. Ann. Intern. Med. 111:355361.

8. Wasnich, R. D., P. D. Ross, L. K. Heilbrun, and J. M. Vogel. 1985. Prediction of postmenopausal fracture risk with use of bone mineral measurements. Am. J. Obstet. Gynecol. 153:745-751.

9. Cummings, S. R., D. M. Black, M. C. Nevitt, W. Browner, J. Cauley, K Ensrud, H. K. Genant, L. Palermo, J. Scott, and T. M. Vogt. 1993. Bone density at various sites for prediction of hip fractures. Lancet. 341:72-75.

10. Melton, L. J., III, E. J. Atkinson, W. M. O’Fallon, H. W. Wahner, and B. L. Riggs. 1993. Long-term fracture prediction by bone mineral assessed at different skeletal sites. J. Bone Min. Res. 8:1227-1233.

11. Morrison, N. A., J. C. Qi, A. Tokita, P. J. Kelly, L. Crofts, T. V. Nguyen, P. N. Sambrook, and J. A. Eisman. 1994. Prediction of bone density from vitamin D receptor alleles. Nature (Land). 367:284-287.

12. Morrison, N. A., R. Yeoman, P. J. Kelly, and J. A. Eisman. 1992. Contribution of trans-acting factor alleles to normal physiological variability: vitamin $\mathrm{D}$ receptor gene polymorphisms and circulating osteocalcin. Proc. Natl. Acad. Sci. USA. 89:6665-6669.

13. Faraco, J. H., N. A. Morrison, A. Baker, J. Shine, and P. M. Frossard. 1989. ApaI dimorphism at the human vitamin D receptor gene locus. Nucleic Acids Res. 17:2150.

14. Hustmyer, F. G., H. F. DeLuca, and M. Peacock. 1993. ApaI, BsmI, EcoRV and TaqI polymorphisms at the human vitamin D receptor gene locus in Caucasians, Blacks and Asians. Human Molecular Genetics. 2:487.

15. Goto, H., K. Chen, J. M. Prahl, and H. F. DeLuca. 1992. A single recepto identical with that from intestine/T47D cells mediates the action of 1,25-dihydroxyvitamin D-3 in HL-60 cells. Biochim. Biophys. Acta. 1132:103-108.

16. Christian, J. C., K. W. Kang, and J. A. Norton, Jr. 1974. Choice of an estimate of genetic variance from twin data. Am. J. Hum. Genet. 26:154-161.

17. Falconer, D. S. 1981. Introduction to Quantitative Genetics. Longman Group Limited, London. 148-169.

18. Li, C. C. 1976. First Course in Population Genetics. The Boxwood Press, Pacific Grove, CA. pp 1-13.

19. Baker, A. R., D. P. McDonnell, M. Hughes, T. M. Crisp, D. Mangelsdorf, M. R. Haussler, J. W. Pike, J. Shine, and B. W. O'Malley. 1988. Cloning and expression of full-length cDNA encoding human vitamin D receptor. Proc. Natl. Acad. Sci. USA. 85:3294-3298.

20. Hsieh, J.-C., P. W. Jurutka, M. A. Galligan, C. M. Terpening, C. A Haussler, D. S. Samuels, Y. Shimizu, N. Shimizu, and M. R. Haussler. 1991. Human vitamin D receptor is selectively phosphorylated by protein kinase $\mathrm{C}$ on serine 51, a residue crucial to its trans-activation function. Proc. Natl. Acad. Sci. USA. 88:9315-9319. 